\title{
CASE REPORT: OLIGOSYMPTOMATIC RHEUMATOID ARTHRITIS PRESENTED WITH AN IMPORTANT HAND DEFORMITY
}

Rodrigo Sarmanho Spohr ${ }^{1, \star}$, Maria Lara Picolo ${ }^{1}$, Ângela Massignan ${ }^{1}$

1.Hospital Moinhos de Vento, Porto Alegre (RS), Brazil.

*Corresponding author: reumatologia.rodrigo@gmail.com

\section{BACKGROUND}

Rheumatoid arthritis (RA) is an autoimmune disease characterized by inflammatory polyarthritis, mainly affecting small joints. This happens due a synovial inflammation, which later forms a granulation tissue that covers the cartilage and subchondral bone, called pannus. The universal symptom in these patients is pain, usually accompanied by edema and prolonged morning stiffness. There is lack of evidence about RA without an obvious clinical complaint of pain; nonetheless, this case reports a RA painless patient that evolved to an irreversible hand deformity. The patient gave her written consent for this publication.

\section{CASE REPORT}

A 31-year-old female sought rheumatological evaluation due to progressive loss of mobility of the 4th and 5th right fingers, starting two years earlier, with sporadic mild pain. She denied trauma or any other symptoms, and had no family history of rheumatological diseases. On physical examination, she had boutonniere deformity on the fifth finger (Fig. 1), as well as thickening of the fourth and fifth proximal interphalangeal (PIP) joint of the same hand. In laboratory diagnostic tests she presented a rheumatoid factor of $55 \mathrm{IU} / \mathrm{mL}$, anti-CCP over $200 \mathrm{U} / \mathrm{mL}$, ESR $31 \mathrm{~mm}$ and CRP $0.88 \mathrm{mg} / \mathrm{dL}$. Magnetic resonance imaging (MRI) of the right hand showed deformities in the fifth finger, with increased flexion of the PIP joint and extension of the distal interphalangeal joint (Fig. 2). Thickening and edema of the capsule-ligament structures were observed at the level of the PIP of the fourth and fifth fingers. This patient was classified with RA, and methotrexate associated with folic acid was initiated. Four months later, she began to experience more significative pain in the affected joints. Leflunomide was associated, and patient underwent a joint infiltration with methylprednisolone acetate. Nowadays she presents a DAS28 score of 3.6 - a moderated activity score.

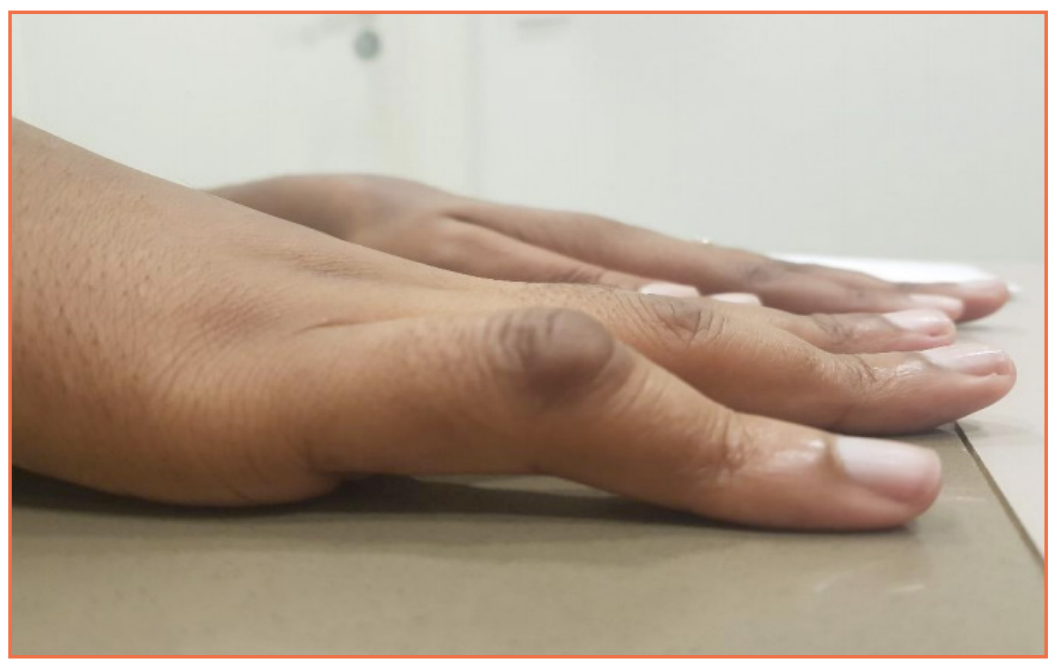

Figure 1. Boutonniere deformity of 5th finger. 


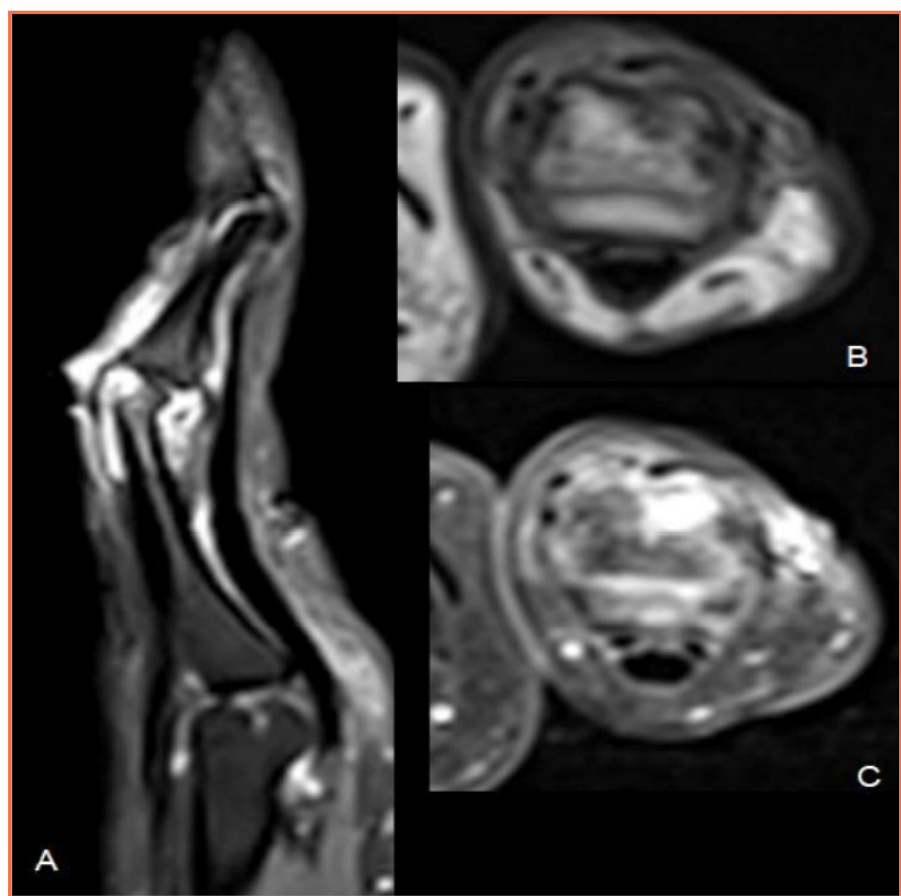

Figure 2. Magnetic resonance imaging of the 5th right finger. (A) Axial images of the PIP with synovitis; (B) T1 with periarticular osteitis and (C) T1 with fat suppression after contrast, with an articular erosion.

\section{CONCLUSION}

This case has a pedagogical purpose: it is a reminder that synovitis must never be underestimated, even if the patient himself does not complain about it. The use of less subjective evaluation tools, such as DAS28, CDAI or SDAl, benefits the patient with a better control of the disease and prevents irreversible joint damages, as this patient unfortunately has. 